\title{
Lady's voice em encontro de náufragos
}

\section{Eugénia Vasques}

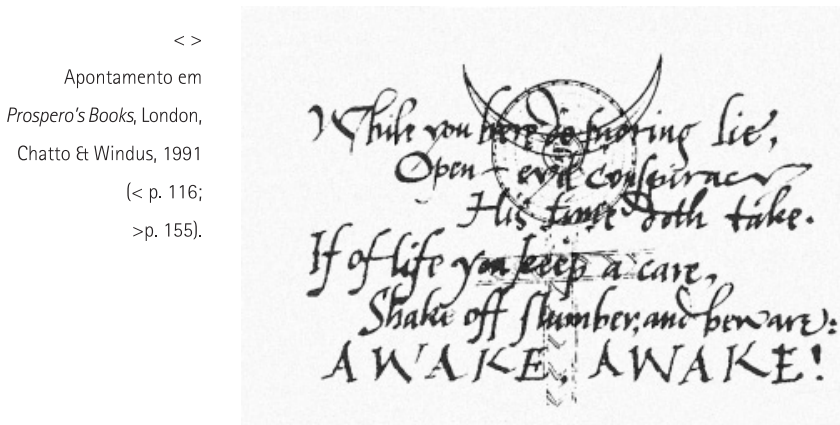

A paginação referida neste artigo está conforme versão

dactiloscrita disponibilizada pela autora.

Eugénia Vasques é investigadora, critica de teatro e ProfessoraCoordenadora da Escola Superior de Teatro e

Cinema/ Instituto

Politécnico de Lisboa. Entre alguns dos livros que publicou estão Jorge de Sena: Uma

ideia de teatro

(1938-71)

[Cosmos, 1998];

Mulheres que escreveram teatro no século XX em Portugal [Colibri, 2001]; João Mota, pedagogo teatral (metodologia e criação) [Colibri/IPL, 2006],

Para a história da encenação em Portugal: $O$ difícil progresso no conceito de encenação no teatro (1837-1928) [ Sá da Costa, 2010].
Próspero morreu, de Ana Luísa Amaral é, no quadro da criação poética contemporânea no feminino, um caso particular de escrita dramática fundada em processos de intratextualidade e intertextualidade literárias sobre fundo mitológico. Este procedimento é recorrente em parte substancial do imaginário cénico das novas gerações, mas enuncia-se em modos mais diversificados do que os que foram utilizados por dramaturgos e dramaturgas das duas metades do século XX. Lembro, a título de exemplo, a escrita dramática mais experimental de poetas como Jorge de Sena, Natália Correia, Fiama Hasse Pais Brandão ou, mais actualmente, a escrita mitocrítica de Armando Nascimento Rosa e a escrita cenocentrada de Carlos J. Pessoa, para citar exemplos opostos.

Esta peça (no prelo), dedicada a Paulo Eduardo Carvalho (falecido subitamente, no mar, em Maio de 2010), teve já duas leituras públicas e uma gravação radiofónica. Próspero morreu, que se define, internamente, um "contrato de voz" (p. 24) 1 , fala justamente de náufragos, "convoca vozes vindas de tempos diferentes e tradições diversas, que falam do amor, do poder, da ambição e da magia", segundo palavras de apresentação do próprio Paulo Eduardo Carvalho. 0 texto, definido pela autora como "drama poético", tem a forma externa, convencional, do "acto único" e ostenta sete personagens, caracterizadas por deterem poderes de modos vários mágicos, figuras oriundas de diferentes universos e estatutos dos dois lados, nas duas barricadas, da poesia: criadores e criaturas. São elas: Ariel e Caliban, de A tempestade de Shakespeare $(\mathrm{I}, 2)$; Penélope e Ariadne, da epopeia e dos mitos clássicos; Bárbara escrava e Luiz, do universo camoniano; e Teseu, da mitologia e também da poesia dramática shakespeariana.

As suas vozes respondem-se (dramaticamente) ou interpolam-se (poeticamente) numa tecedura de versos que em muitos momentos, metalinguisticamente, nos falam, pela voz das criaturas, do próprio trabalho da poesia em exercício e dos seus universos diferenciados, como o fazem Bárbara ou Penélope. Esta refere mesmo:
Texto dedicado a Frei José Augusto Mourão, dominicano, semiólogo poeta que nos deixou no dia 5 de Maio de 2011.

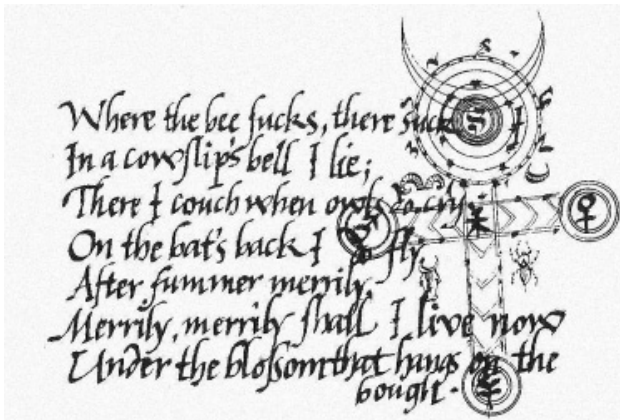

Afastai-vos daqui!

Não chega o que dissestes,

que aqui fomos chamados para velar aquele

que tanto tempo escravizou Caliban?

Porque havia de ser que aqui viemos

velar junto à maldade e ao poder?

É pouca a explicação que ofereceis, Ariel

Porque nos encontramos todos nesta ilha?

Foi um naufrágio, o que aqui nos guiou?

Ou cápsula de luz,

que, transportada aos trambolhões no tempo,

aqui nos reuniu?

Gregos e outros, vindos de outros tempos,

e esse, escuro e informe

mas amado,

forjado por um sonho isabelino...

0 que nos une aqui?, perguntarei.

Terá de me caber a mim, Penélope,

que sequer emergi de bastidores

e nem conselhos sei,

mas pressinto o que vem desde o principio,

o inicio de tudo? (p. 24)

A reunião, de ressonância pessoana, destas figuras que são colocadas na cena, desde a $1^{\text {a }}$ didascália, de modo significativo e assimétrico (p. 2), parece ser devida à morte de Próspero, aquele que deixou de herança a morte do amor (p. 25) e cujo corpo talvez estejam ali para velar: "aqui fomos chamados para velar aquele//que tanto tempo escravizou Caliban?//Porque havia de ser que aqui viemos//velar junto à maldade e ao poder?" (p. 24).

Trata-se igualmente de uma peça que, como uma tragédia antiga, revela configuração cíclica - um dia (da alvorada ao cair da noite) - e cuja acção, de contornos incertos, um tanto enigmáticos para as próprias figuras intervenientes, se passa numa ilha, à volta de uma fogueira. Em cena, porém, na cena imaginada por Ana Luisa Amaral, estas figuras reúnem-se, em planos diferenciados do palco 

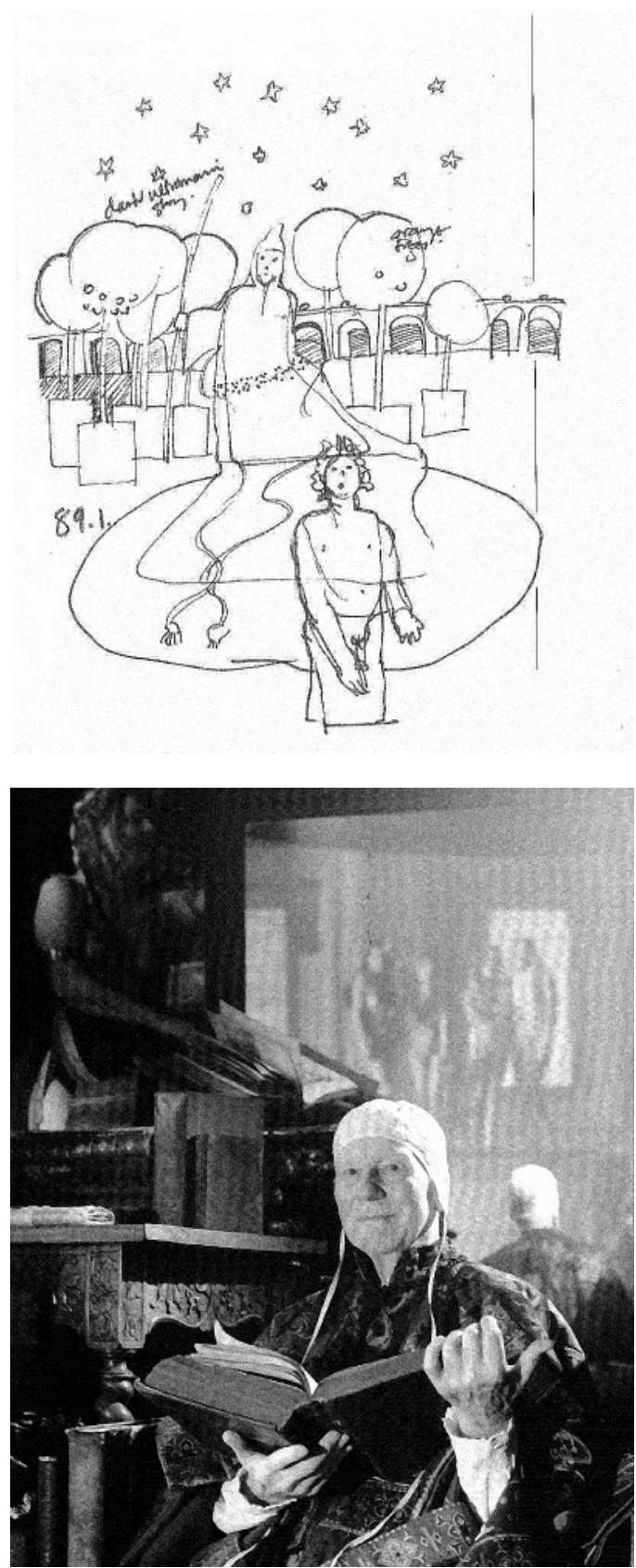

"à italiana", e a sua existência não é autónoma pois está já, no imaginário colectivo, para sempre ligada, emparelhada, a poderosas histórias de amor/poder/traição/perda: Ariadne/Teseu, Ariadne/Caliban, Penélope/Ulisses (que é somente referido), Bárbara/Luiz (de Camões).
Ariel mantém, aqui, o que é a sua origem etimológica hebraica, o ser duplo (ele/ela), "figura [que] parece saber das vidas todas" (p. 2), "fantasia, mais real que sonho" (p. 5) e que celebra a diferença:

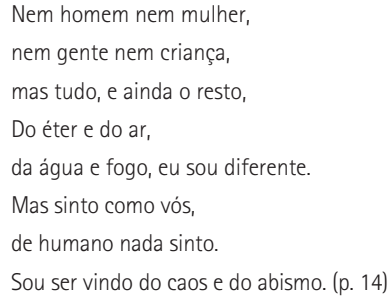

É igualmente um ser não omnisciente, como parecia ser ao assumir o papel semelhante ao de Prólogo, embora esteja consciente do que não é nesta ficção: "Não é minha função adiantar,//mas perguntar://Quem viverá?//Ou quem irá morrer?" (p. 24). Ariel é ainda um contraponto, presencial, da ausência de Próspero, morto, cujo caixão fechado é trazido para cena, símbolo, mas mudo, do poder que ninguém chora. E como Próspero é símbolo opressivo do poder: "Ninguém chora o poder//Sem liberdade é o poder um monstro" (p. 15). Próspero será, assim, desigual, em monstruosidade, de Caliban que, ao contrário desse símbolo da repressão sem voz, pela magia do amor será libertado ( $p$. 15) e dotado da sensatez do verbo, da fala: "Traz-me uma escada//que me faça subir a paraiso,//. . .meu olhar" (p. 16).

Do ponto de vista do trabalho poético sobre os elementos dramáticos, para além da perturbação permanente do diálogo dramático - por processos como a já referida interpolação - ou da constante alteração da estabilidade das falas das personagens que se confundem ou fundem intertextualmente com discursos vindos - tal como estas figuras - de "desvairadas partes", há ainda a evidente reconfiguração dos apartes que, nesta peça, se transformam e amplificam em solilóquios de grande impacto lírico como ocorre com Ariadne nas sequências que antecedem a sua confissão a Teseu (pp. 7-9).

Concluindo - e para usar um adjectivo caro a Ariadne e Caliban - /, direi que esta peça, de grande cultura e sensibilidade poéticas, se auto-enuncia como um texto da pós-pós modernidade, tecida de fios, literalmente, de memórias, literalmente, de bocados e de "síncopes longas", de exercícios de memória e de histórias de e para recordar. "E não é já assombro um feito tal?" (p. 31) como interroga Ariel?

Ariadne - como os nossos amados irmão e amigos que partiram - também morreu. "Que mais [a] desejar senão memória?" (p. 30)
Esboço em Prospero's

Books, London,

Chatto \&t Windus, 1991 p. 153.

John Gielgud em Os livros de Próspero (1991),

de Peter Greenaway. 